\title{
Religião, cultura e políticas públicas no Amapá: religiosidade, cerâmica e encantaria na tradição das Louceiras do Maruanum
}

\author{
Célia Souza da Costa ${ }^{1 *}$ \\ Elivaldo Serrão Custódio ${ }^{2 *}$
}

\section{RESUMO}

A tradição do criar-saber-fazer das louceiras do Maruanum é marcada por rituais, pela encantaria, religião e cultura. Devido a eminência da extinção dessa prática secular apontada pela antropóloga Alicia Coirolo (1991) surge a necessidade de políticas públicas na área cultural e social. Desde a retirada da argila até a queima da cerâmica, as louceiras obedecem ao processo ritualístico que envolve a crença na Mãe do Barro e cumprem as etapas do criar-saber- fazer das louças. Portanto, o objetivo desse artigo é estabelecer uma relação entre a cultura, a religião, o ritual e a importância da ação de políticas públicas para permanência dessa prática cultural. Esse estudo utilizou a metodologia de pesquisa qualitativa a partir da observação in loco. Alguns autores colaboram para a discussão teórica como Costa (2014), Pelegrini e Funari (2008) e Porta (2012). A pesquisa aponta a urgência de políticas públicas para a manutenção da prática ceramista das louceiras do Maruanum, especialmente por parte do poder público que precisa agir por meio de intervenções de educação ambiental patrimonial e estabelecer ações afirmativas visando a perpetuação desse criar-saber-fazer.

Palavras-chave: Louceiras do Maruanum. Religião. Cultura. Políticas Públicas. Amapá.

1 Doutoranda em Educação pela Pontifícia Universidade Católica do Paraná/PUCPR. Mestra em Direito Ambiental e Políticas Públicas pela Universidade Federal do Amapá/UNIFAP. Bacharel em Comunicação Social pela Faculdade SEAMA. Currículo lattes: http://attes. cnpq.br/6191102948827404.E-mail:celia.amapa@hotmail.com

2 Pós-doutorando em Educação pela Universidade Federal do Amapá/UNIFAP. Doutor em Teologia pela Faculdade EST. Mestre em Direito Ambiental e Políticas Públicas pela Universidade Federal do Amapá /UNIFAP. Currículo lattes: http://lattes.cnpq. br/8819683729192070.E-mail:elivaldo.pa@hotmail.com 


\title{
RELIGION, CULTURE AND PUBLIC POLICIES IN AMAPÁ: RE- LIGIOSITY, CERAMICS AND ENCHANTMENT IN THE MARU- ANUM LOUCEIRAS TRADITION
}

\begin{abstract}
The tradition of the creation-know-how of Maruanum wailers is marked by rituals, enchantment, religion and culture. Due to the eminence of the extinction of this secular practice pointed out by the anthropologist Alicia Coirolo (1991) arises the need of public policies in the cultural and social area. From the removal of the clay to the burning of the pottery, the madmen obey the ritualistic process that involves the belief in the Mother of Clay and fulfill the steps of create-know-how of the dishes. Therefore, the purpose of this article is to establish a relationship between culture, religion, ritual and the importance of the action of public policies for the permanence of this cultural practice. This study used the methodology of qualitative research from in loco observation. Some authors collaborate in the theoretical discussion as Costa (2014), Pelegrini and Funari (2008) and Porta (2012). The research shows the urgency of public policies for the maintenance of ceramist practice of louceiras the Maruanum, especially by the government that must act through balance environmental education interventions and establish affirmative action aimed at perpetuating this rear-know-how.
\end{abstract}

Keywords: Louceiras do Maruanum. Religion. Culture. Public policy. Amapá.

\section{Introdução}

As culturas indígenas assim como as culturas africanas são preponderantes no estado do Amapá localizado na região Norte do Brasil. Essas duas culturas apresentam uma relação subjetiva com a natureza e seus elementos.

Essa relação com as crenças indígenas e africanas se cristalizam no respeito aos encantados, presentes nas lendas e nos mitos, das tradições culturais locais, do capital simbólico, do universo cultural, do criar, dos saberes, dos fazeres e tradições, como é o caso das Louceiras do Maruanum. 
A arte cerâmica amapaense aponta para uma hegemonia da presença feminina em sua confecção, como é o caso das Louceiras do Maruanum. Além das simbologias e grafismos que identifica qual louceira produziu a peça, onde desde a retirada do barro até o processo de queima da louça são marcados por rituais. É no "ritual" da extração da argila que se processa todo o diálogo das louceiras que creem na "Mãe do barro"3 como a guardiã do barreiro ${ }^{4}$.

Para vislumbrar a cultura dessas mulheres amazônidas recorremos a metodologia qualitativa, na qual a pesquisa enquadrou-se como um estudo exploratório por meio da observação in loco, portanto nas comunidades de Santa Luzia e Carmo do Maruanum. Para análise dos dados apresentados utilizamos a hermenêutica fenomenológica. Então, a pesquisa qualitativa é capaz de apresentar resultados que não podem ser vislumbrados nas análises quantitativas, "como a diversidade das práticas sociais [...] a dinâmica social da construção identitária" (ALAMI, DESJEUX, GARABUAU-MOUSSAOUI, 2010, p.19).

Dentre os autores utilizados para construir esse trabalho destacamos Costa (2014) autora da dissertação intitulada "Patrimônio Cultural do Amapá: o caso das Louceiras do Maruanum em observância ao Princípio da Equidade Intergeracional”, na qual explica à pesquisa a urgência de políticas públicas para preservação e continuidade geracional do criar-saber-fazer das mulheres ceramistas. Também utilizamos Pelegrini e Funari (2008) que na obra "O que é Patrimônio Cultural Imaterial" destacam o reconhecimento da imaterialidade das tradições e saberes e a importância dos registros dos bens imateriais brasileiros. Para complementar a análise dos dados mencionamos Porta (2012) que retrata em dossiê a Política de Preservação do Patrimônio Cultural do Brasil contribuindo com as informações sobre as ações realizadas pelo Instituto do Patrimônio Histórico e Artístico Nacional (IPHAN).

Nesse artigo abordamos no primeiro subitem Caminhos da pesquisa destacando a utilização de uma metodologia qualitativa e

Ser cultuado pelas louceiras do Maruanum, que vive na área de onde se extrai a argila para a produção da cerâmica utilitária (COSTA, 2014).

4 Local de onde se extrai a argila para a confecção da louça (COSTA, 2014). 
de estudo exploratório tendo como instrumento o diário de campo. No segundo subitem apresentamos O criar-saber-fazer das louceiras do Maruanum em eminência de extinção. No terceiro subitem discutimos as políticas públicas para Cultura especificamente sobre as Ações do IPHAN (AP) E SECULT (AP) voltadas à cerâmica das louceiras do Maruanum. No quarto subitem mencionamos uma Proposta para perpetuação do ofício tradicional das louceiras do Maruanum e por último discorremos as considerações finais.

Portanto, as louceiras do Maruanum constituem parte do patrimônio material e imaterial do estado do Amapá. Falar sobre essa tradição, crenças e saberes é retratar a religião, cultura e a urgência de políticas públicas para cultura, para o criar-saber-fazer do ofício dessas ceramistas com o intuito de dar visibilidade para essas mulheres que carregam uma história de vida e de resistência cultural. Além disso, o objetivo desse artigo é estabelecer uma relação entre a cultura, a religião, o ritual e a importância da ação de políticas públicas para permanência da prática tradicional do criar-saber-fazer louças de barro.

\section{Caminhos da pesquisa: observar é conhecer}

Esse trabalho é um estudo exploratório de natureza qualitativa que adotou a pesquisa de campo, com observação in loco e a entrevista como forma de investigação. A orientação metodológica para análise desse trabalho foi à hermenêutica fenomenológica (RICOEUR, 1976).

Os dados das pesquisas de campo foram extraídos do diário de campo de Célia Souza da Costa, uma das autoras desse artigo que por dois anos pesquisou sobre a tradição ceramista das louceiras do Maruanum que resultou na dissertação de mestrado em 2014, defendida na Universidade Federal do Amapá pelo Programa de Mestrado em Direito Ambiental e Políticas Públicas.

As observações in loco ocorreram nos anos de 2012 e 2013 no barreiro, onde foi possível catalogar imagens e vídeos do momento da extração da argila; como as louceiras moldam as peças; e como realizam a queima da louça. As entrevistas também foram 
instrumentos de pesquisa primordiais para o traçado desse artigo, na qual as louceiras puderam falar sobre a Mãe do barro e a tradição do criar-saber-fazer da louça utilitária.

$\mathrm{O}$ distrito do Maruanum está localizado as margens do rio Maruanum, distante cerca de $80 \mathrm{~km}$ de Macapá, capital do estado do Amapá. Para chegar às comunidades do Maruanum é possível via terrestre (BR 210) ou fluvial. A formação social dessa comunidade sofreu influências indígenas e negras, trocas que resultaram na crença da Mãe do barro e nos encantados que caracterizam uma forma diferenciada de religiosidade, de viver e ler o mundo (COSTA, 2014, p. 41).

Assim, esse legado simbólico permeou essa relação subjetiva dos índios e negros com a natureza. Tudo começa com a representação de afetividade com aquilo que tem vida: a mata, a terra, o vento, o rio e os animais. Isso se materializa na passagem dessas forças para o cotidiano dos comunitários, especialmente na forma de criar, saber e fazer, nesse caso "jeito" de produzir a cerâmica do Maruanum (COSTA, LIMA e CUSTÓDIO, 2016, p. 202).

\section{O criar-saber-fazer das louceiras do Maruanum em eminência de extinção.}

A preservação do criar-saber-fazer das louceiras do Maruanum é condição imprescindível para manutenção do bem cultural material e imaterial que por meio da criatividade e do conhecimento se materializa na louça de barro. Porém, o desafio é encontrar alternativas viáveis para se chegar a esse objetivo, pois a presente geração que deveria ser a guardiã desta herança cultural está desmotivada e não consegue visualizar a verdadeira carga cultural e histórica que tal ofício carrega.

Coirolo (1989) em pesquisa de campo no Distrito do Maruanum chegou à conclusão que o criar-saber-fazer das louceiras do Maruanum estava em contagem regressiva para ser extinta devido a vários fatores como: a) dificuldades que as louceiras têm dar continuidade em suas tradições culturais por não haver interesse dos mais novos em conhecer e se apropriar desses saberes local; 
b) dificuldade que a comunidade tem em conseguir a matéria prima para confecção das louças de barro; c) falta de logística e de políticas públicas de incentivo para continuidade de suas tradições culturais, entre outras.

Como pode ser extinta a materialidade de um bem cultural tão importante como as louceiras do Maruanum? Quais as políticas públicas culturais existentes para que esse patrimônio material e imaterial não venha a desaparecer?

No decorrer da pesquisa de campo procurou-se identificar quais as políticas públicas voltadas às louceiras do Maruanum, porém surgiram várias dificuldades em conseguir conversar e entrevistar os responsáveis pelos setores dos órgãos Instituto do Patrimônio Histórico Artístico Nacional (IPHAN/AP) e Secretaria Estadual da Cultura (SECULT/AP). Assim, as análises foram baseadas nos dados colhidos em pesquisa de campo, aqueles que foram disponibilizados ou possíveis.

\section{Ações do IPHAN (AP) E SECULT (AP) voltadas à cerâmica das louceiras do Maruanum}

Em pesquisa de campo realizada no dia 11 de abril de 2012 à Superintendência do Instituto do Patrimônio Artístico Nacional (IPHAN-AP) localizado na parte interna da Fortaleza de São José de Macapá verificou-se que existe um arquivo com documentos sobre as louceiras do Maruanum. Os documentos foram elaborados no dia 15 de setembro de 2009 por uma técnica do IPHAN. Tal documentação foi denominada como Fontes Documentais Inventariadas. Assim, o criar-saber-fazer da cerâmica do Maruanum é reconhecido pelo IPHAN-AP como Referência Cultural Inventariada. Diz o documento do IPHAN-AP com a descrição deste ofício:

Considerado um ofício tradicional da comunidade do Maruanum, o processo de fabricação das cerâmicas vai desde a coleta da matéria prima utilizada na confecção das peças até a sua queima. Entre os materiais empregados na produção ceramista estão às cinzas das cascas de duas etnovariedades de cariapé (Licania spp), identificadas localmente como 
carepé branco e carepé vermelho que são insubstituíveis no processo, de acordo com relatos locais. As cinzas são misturadas ao barro dando-lhe maior plasticidade. As técnicas das louceiras do Maruanum são transmitidas de uma geração a outra. Nesta comunidade de Maruanum, a 120 $\mathrm{km}$ de Macapá (AP) um grupo de mulheres descendentes de um antigo quilombo desenvolvem a arte centenária da fabricação de louças de barro preservando as mesmas técnicas utilizadas por suas antepassadas. Entre os meses de agosto e novembro, antes das águas da chuva encher os campos de várzea, elas saem em mutirão para coletar o barro. Todo o processo segue um ritual secular de tradições indígenas. Apesar de Maruanum ser um núcleo tradicional do ofício das ceramistas, Mazagão também teria pessoas praticando esta atividade artística e econômica (IPHAN-AP, Anexo 01: Referências culturais inventariadas, $\mathrm{n}^{\circ} 20,2009$ ).

Entende-se que o registro por meio de documentação é fundamental, pois o ofício das louceiras do Maruanum já é uma referência cultural inventariada do Estado do Amapá. Consta nesse documento o registro da monografia de Maria do Socorro Araújo e Soraya Costa, que tem como título Maruanum: resgate da cultura do artesanato em cerâmica, ano 2005 do Curso de Artes da Universidade Federal do Amapá utilizada como Fonte documental inventariada, $\mathrm{n}^{\circ}$ 58, 2009. O trabalho tinha como objetivos resgatar, registrar e divulgar a origem e a importância do artesanato em cerâmica desenvolvido no Distrito do Maruanum, abordando aspectos utilizados durante a extração (coleta de matéria-prima), produção e armazenamento das peças, destacando e analisando os rituais históricos.

Como fontes documentais inventariadas, a técnica do IPHAN (AP) citou a monografia de autoria de Euclides de Pinho et. e al, tendo como título Cerâmica utilitária do Maruanum, de setembro de 1996 do curso de Licenciatura de Educação Artística da Universidade Federal do Amapá sendo uma Fonte documental inventariada, $\mathrm{n}^{\circ}$ 061, 2009. O trabalho descreve, sucintamente, o processo de fabricação das cerâmicas na localidade do Maruanum. O mais interessante do trabalho são os desenhos coloridos ao final e algumas fotocópias de recortes de jornais que tratam do quilombo do Curiaú, dos negros no Amapá, do Marabaixo e da Festa de São Tiago. 
Como registro de audiovisual foi citado o documentário " $A s$ mãos da mãe do barro" de Gavin Andrews, produzido por Castanha Filmes no ano de 2005, sendo uma Referência cultural inventariada, n²01, 2009. O audiovisual tem duração de 15 minutos. Também foram citados dois vídeos produzidos pela Fundação de Cultura do Amapá que é a atual Secretaria de Estado de Cultura do Amapá, não há referência de datas, os vídeos evidenciam o artesanato e a cerâmica da comunidade do Maruanum.

Outro registro realizado pelo IPHAN-AP foi o artigo de Alícia Coirolo, denominado Atividades e Tradições dos Grupos Ceramistas do Maruanum (AP), publicado no Boletim do Museu Paraense Emilio Goeldi, na série Antropologia, no ano de 1991, consta como Referência cultural inventariada, $n^{\circ} 201,2009$. Tal estudo foi apresentado no $46^{\circ}$ Congresso de Americanistas em Amsterdam em 1988.

O livro de Alarico José da Cunha Júnior e Fernando A. Genschow, intitulado Amapá: um estudo para colonização publicado pelo Instituto Nacional de Imigração e Colonização em 1958 também é uma Referência cultural inventariada, $n^{\circ} 209,2009$. O livro relata a colonização do Território Federal do Amapá, principalmente com a imigração japonesa na região do rio Matapi e descreve o processo de trabalho das ceramistas da comunidade do Maruanum, há várias fotografias em preto e branco da atividade das ceramistas.

Foi registrado pela técnica do IPHAN-AP como Referência cultural inventariada, $\mathrm{n}^{\circ} 210,2009$, a produção de áudio tipo disco digital realizado no Encontro dos Tambores, no ano de 1996, onde o grupo folclórico da Comunidade do Maruanum gravou as seguintes músicas de marabaixo e batuque: "Eu vou-me embora; É de manhã, é de madrugada".

A Superintendência do IPHAN/AP tratou o ofício das louceiras do Maruanum como referência cultural do Estado do Amapá. Sobre isso, Porta (2010, p.124) assegura que um dos principais avanços do IPHAN/AP foi o mapeamento das referências culturais do Estado do Amapá. Nesse sentido, Porta (2010, p.224) diz que a atividade de pesquisa e documentação do patrimônio cultural 
é uma linha de ação prioritária da política de preservação, pois ela possibilita ampliar sua representatividade e significado social, além de servir como suporte para o planejamento de ações. Enfim, a valorização das referências culturais fomenta a participação social, a afirmação identitária e a cidadania.

Em relação ao Inventário Nacional de Referências Culturais trata-se de um instrumento de documentação e produção de conhecimento sobre o patrimônio cultural de natureza imaterial regulamentado pela Instrução Normativa $n^{\circ} 01 / 2009$, uma vertente do Decreto $\mathrm{n}^{\circ} 3.551 / 2000$ que institui o Registro de Bens Culturais de Natureza Imaterial. A metodologia atribuída ao inventário é a identificação e estudo de um determinado território, de expressões culturais praticadas ao longo dos anos que são referências de identidade e de memória para as comunidades que as praticam. Cada inventário necessita de pesquisa bibliográfica e de campo com entrevistas, depoimentos, documentação sonora e audiovisual. Sendo que as informações obtidas através do inventário auxiliam a instrução dos processos de registros de bens imateriais, fornece conteúdo para as ações de promoção e orienta as ações de fomento do Programa Nacional de Patrimônio Imaterial (PORTA, 2010, p.45).

Apesar de existirem Referências Culturais Inventariadas sobre as ceramistas do Maruanum,nota-se que o IPHAN/AP precisa avançar em relação às ações de registro de bens culturais de natureza imaterial, pois o Ofício das Louceiras do Maruanum já é reconhecido como uma referência cultural inventariada e uma vez registrado no Livro de Registro de Saberes, além de agregar visibilidade também será contemplada pelo Plano de Salvaguarda que é formado por um conjunto de ações destinados a apoiar a continuidade das expressões culturais registradas como patrimônio cultural.

Sobre isso, foi constatado por meio da pesquisa de campo através de entrevistas com as louceiras do Maruanum que há um certo o descontentamento em relação à atuação do IPHAN/AP, assim como a ausência de ações e projetos voltados para o reconhe- 
cimento do ofício da cerâmica das comunidades de Santa Luzia e Carmo do Maruanum que compõem o Distrito do Maruanum.

Em relação as ações da SECULT/AP para a difusão do Ofício das Louceiras do Maruanum, a pesquisa de campo apontou que as ações desse órgão sempre estiveram limitadas à elaboração de materiais gráficos, sonoros e audiovisuais, como por exemplo, a Revista Cultura Agora (2012) que evidenciou a matéria "A arte de fazer louças pelas mãos das mulheres do Maruanum”. O certo é que a SECULT/AP durante estes últimos anos não atuou com nenhum projeto específico com atividades voltadas para o fortalecimento, fomento e reconhecimento do Ofício das Louceiras do Maruanum. Durante a pesquisa de campo, um servidor do órgão concedeu a seguinte entrevista:

O Sistema de Referências Culturais do Estado do Amapá está na fase final, pois o Projeto de Lei sobre este assunto já foi revisado e aprovado pelo Conselho Estadual de Cultura, agora será encaminhado para as demais instâncias do governo até a lei ser sancionada. Este documento transformado em lei irá assegurar as políticas públicas da cultura no Amapá, como o financiamento da cultura que é um dos grandes entraves, tanto que somente seis estados brasileiros terão direito aos recursos do Fundo Nacional de Cultura, devido à maioria dos estados ainda não terem organizado os seus sistemas. Ao final do ano de 2014, a perspectiva é que a lei seja aprovada para ser encaminhada para Brasília para que o Estado do Amapá receba recursos do Fundo Nacional de Cultura, o que será um grande legado. Existe um projeto da SECULT-AP voltado para a área do artesanato que inclui as louceiras do Maruanum com o fomento e comercialização que será colocado em prática ainda este ano. Dentro da Lei do Sistema de Referências Culturais do Estado do Amapá está previsto a criação do sistema patrimonial, pois o Estado do Amapá erra quando não há o registro da memória do bem cultural, é necessário que o Amapá esteja no Sistema de Indicadores Culturais. ${ }^{5}$

Nesse sentido, a pesquisa de campo revelou que a SECULT/ AP prioriza o desenvolvimento de ações voltadas para a realização das festas tradicionais, como o Ciclo do Marabaixo, o Aniversário da Cidade de Macapá, a Festa de São José e o Encontro dos Tambores, para assegurar o cumprimento do calendário cultural. Até o

Entrevista concedida à autora, em 04 de março de 2014, na SECULT/AP. 
momento inexiste o registro do Sistema de Referências Culturais do Estado do Amapá, o que marca a dificuldade que este órgão enfrenta em relação ao trato dos bens culturais de natureza material e imaterial. Fomentar ações culturais que venham envolver comunidades com potencial de bens culturais ainda não é uma realidade. Enquanto, a valorização, zelo e reconhecimento dos bens culturais do Estado do Amapá, como é o caso das louceiras do Maruanum não acontece, o ofício cerâmico tradicional aguarda os órgãos ligados a cultura consigam desenvolver políticas públicas para esta área do patrimônio cultural.

\section{Proposta para perpetuação do ofício tradicional das louceiras do Maruanum}

A intervenção para a perpetuação do ofício tradicional das Louceiras do Maruanum é necessária e urgente, diante do diagnóstico científico de ameaça de desaparecimento deste criar-saber-fazer que é um bem cultural relevante, no qual as futuras gerações tem o direito de conhecer e praticar. Para a proposição interventiva, inserem-se os exemplos bem-sucedidos da cerâmica de São Gonçalo Beira Rio (Estado do Mato Grosso) e das Paneleiras de Goiabeiras (Estado do Espírito Santo). Porém, vale ressaltar que é fundamental a participação do IPHAN/AP e SECULT/AP neste processo de intervenção.

Outro fator importante é a organização das famílias que habitam no Distrito do Maruanum, especialmente as famílias das louceiras. Para isso, devem ser organizados encontros com a comunidade para a apresentação de documentários sobre as Louceiras do Maruanum juntamente com oficinas de integração e de educação ambiental patrimonial com o objetivo despertar nos comunitários a autoestima, o sentimento de pertencimento e de responsabilidade identitária. Depois, seria importante a inscrição do Ofício das Louceiras do Maruanum no Livro de Registro de Saberes como bem cultural de natureza imaterial, o que garante visibilidade ao patrimônio e a instituição do Plano de Salvaguarda. Cabe ao IPHAN/AP, SECULT/AP, Fundação Municipal de 
Cultura de Macapá (FUMCULT) e a Associação das Louceiras do Maruanum (ALOMA) solicitarem o registro.

A ALOMA deve estar fortalecida e unida, com a documentação da instituição e das associadas bem organizada. Como exemplo de organização e cooperatividade, citamos a Associação de Artesãos de São Gonçalo Beira Rio, que conseguiu instalar uma loja no Centro Cultural do bairro, espaço cedido pela Prefeitura Municipal de Cuiabá. Para manter a loja sempre aberta os associados se revezam todos os dias da semana.

Figura 01: Ceramistas de São Gonçalo Beira Rio.

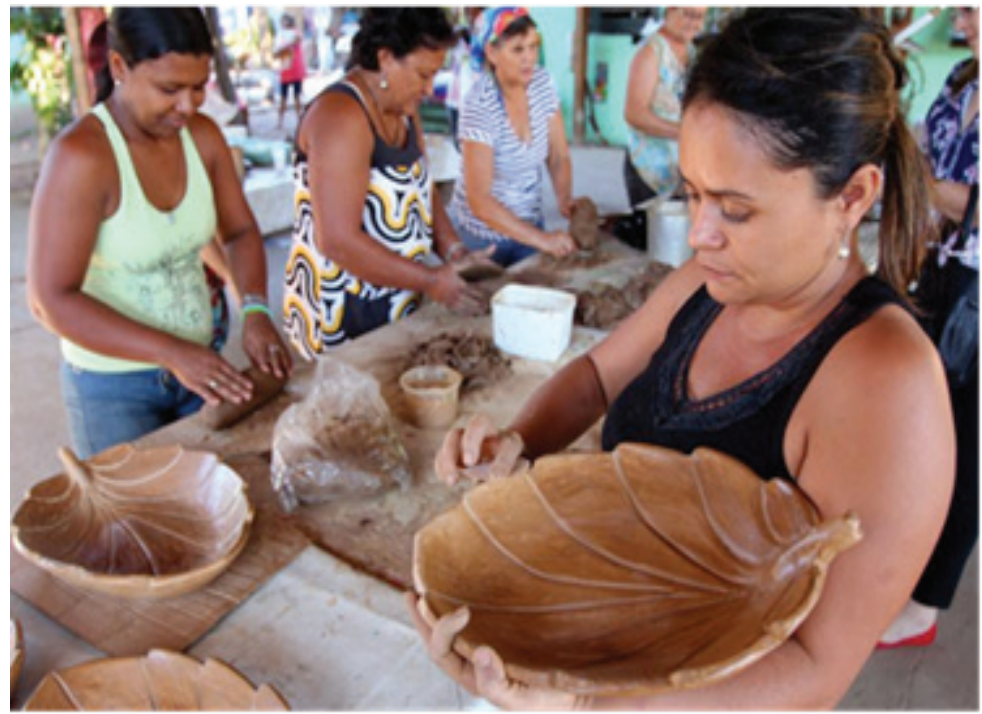

Autoria: Rufano Bombo (2012).

O segundo exemplo é a Associação das Paneleiras de Goiabeiras (APG), entidade criada em 1987 para proteger a categoria na defesa de seus interesses e das condições objetivas da permanência do ofício ceramista. Segundo o Dossiê do IPHAN, a Associação tem sido o principal canal de negociação das paneleiras junto ao poder público e à iniciativa privada, na busca de apoio para a fabricação e promoção dos produtos, na conquista de patrocinadores, material promocional, novos espaços de apresentação e 
vendas dos produtos. Assim, deveria funcionar a Associação das Louceiras do Maruanum (Figura 02), onde todas as atividades e atribuições seriam divididas para manter o espaço aberto e a partir de uma articulação associativa solicitariam ao poder público, recursos para a reforma do local.

Figura 02: Sede da Associação

das Louceiras do Maruanum.

Autoria: Célia S. da Costa (2012).

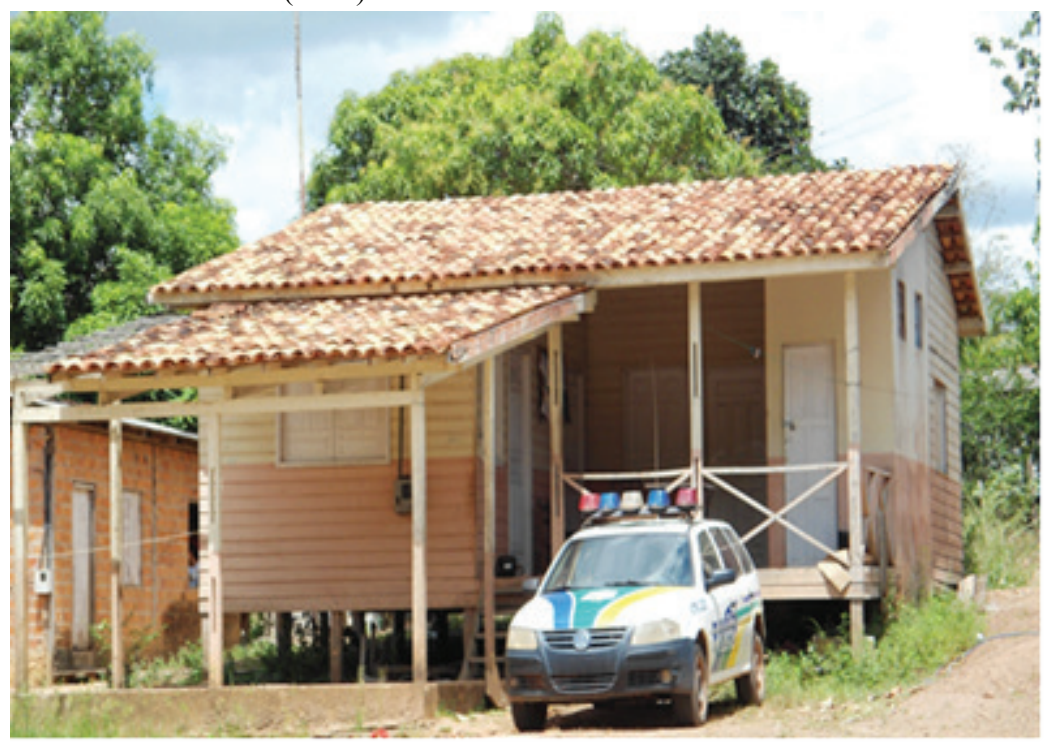

Outra experiência exitosa é da comunidade de São Gonçalo Beira Rio que está localizada as margens do rio Cuiabá, onde existe uma infraestrutura básica para o fomento do turismo comunitário com casas que se transformaram em peixarias caseiras, casas de chá com café da manhã e da tarde recheadas de quitutes de Mato Grosso, lá existe uma espécie de calçadão arborizado, local em que os turistas e visitantes sentam-se para comer e apreciar a paisagem ao longo do rio. Além disso, as artesãs ministram cursos de produção de cerâmica em suas residências para turistas e alunos de escolas da região (SANTOS, 2010, p.09). 
Figura 03: Cerâmica de São Gonçalo Beira Rio.

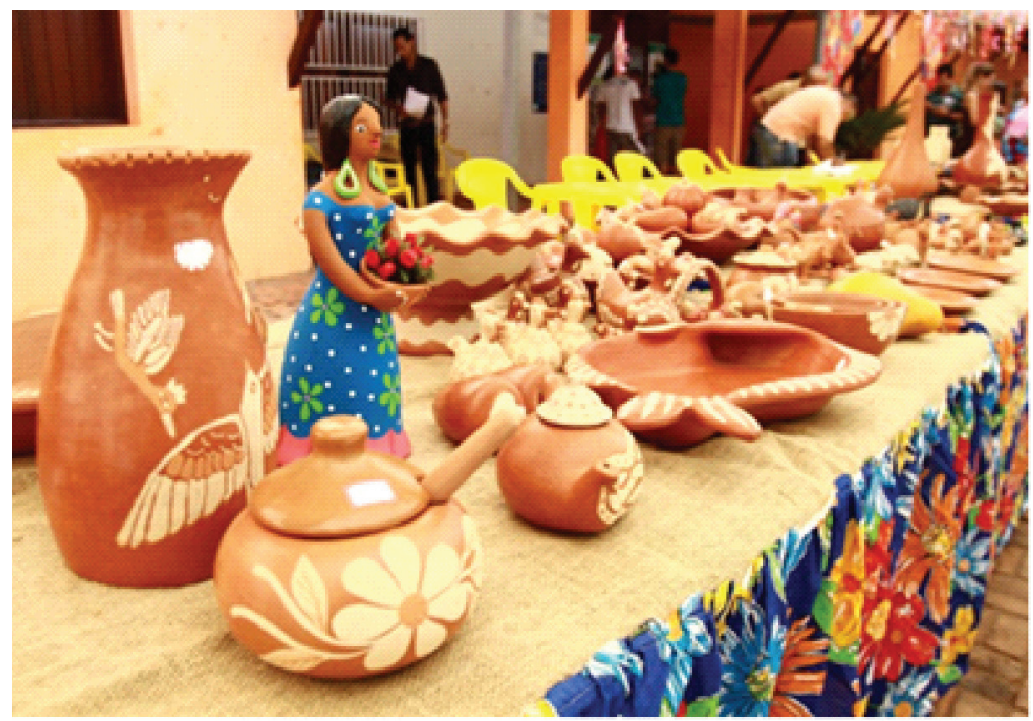

Autoria: Mário kichese (2011).

A mesma vocação para o turismo comunitário possui as comunidades de Santa Luzia e Carmo do Maruanum que são agraciadas pelo Rio Maruanum e por uma beleza natural única (Figura 04), onde é possível estruturar lojas de artesanato com exposição cerâmica, degustação de comidas típicas, onde os turistas poderiam fazer passeios de canoa, praticar a pescaria esportiva e realizar visitas ecológicas com a ida ao local de onde se extrai o barro, aos roçados, casas de farinha e principalmente oferecer ao visitante a oportunidade de manusear a argila e participar de oficinas de cerâmica nas casas de barro das louceiras.

Outro atrativo seria apresentações dos grupos de marabaixo das comunidades do Distrito do Maruanum e exposições de fotos das festas religiosas, onde são festejados os Santos das localidades como é o caso de Santa Luzia. Todas essas atividades seriam realizadas por guias comunitários que uma vez capacitados pela Secretaria Estadual de Turismo do Amapá (SETUR-AP) e Instituto Municipal de Turismo de Macapá (MACAPATUR) poderiam receber turistas e visitantes durante todo o ano por meio de pacotes firmados entre a ALOMA junto às empresas de turismo de Macapá. 
Figura 04: Orla da Comunidade do Carmo do Maruanum.

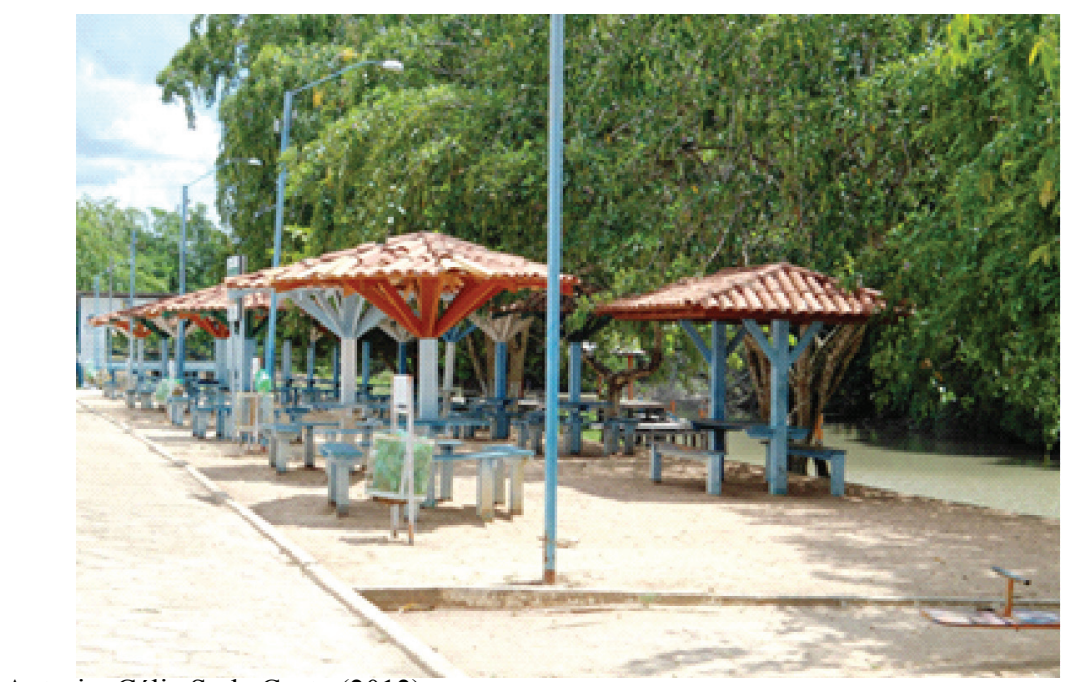

Autoria: Célia S. da Costa (2012).

A esse respeito, o simples registro do bem de natureza material ou imaterial não assegura a sua preservação, porém traz uma série de medidas que viabilizam um plano efetivo de salvaguarda. Uma vez que o ofício das louceiras do Maruanum seja registrado, entra em cena o Plano de Salvaguarda com a formação de um Comitê Gestor formado por representantes do IPHAN, da comunidade envolvida, do Estado e da Prefeitura (PELEGRINI e FUNARI,2008, p. 75).

O plano de salvaguarda abrange estratégias e demandas visando a melhoria das condições sociais, ambientais, materiais de produção e reprodução e na transmissão dos saberes, práticas e técnicas associadas ao bem; além de apoiar na organização e a capacitação dos grupos envolvidos para a autogestão do seu patrimônio; a criação de centros de referência do bem registrado; apoio institucional para a construção de parcerias; contínua educação patrimonial vinculada ao bem e etc (COSTA, 2014, p.110).

Com todas essas ações as comunidades de Santa Luzia e Carmo do Maruanum estariam mais motivadas, organizadas e a tendência é que a juventude se interessasse pela conservação e preservação do criar-saber-fazer do ofício cerâmico das louças 
de barro, com formações específicas de guarda e educação patrimonial voltada às famílias das louceiras que também gerariam renda nas comunidades (COSTA, 2014, p.110).

Vale ressaltar que outra ação importante para a perpetuação do ofício tradicional das louceiras do Maruanum é inserir no currículo escolar local toda a trajetória histórica do ofício ceramista, especialmente na disciplina História, Artes, Geografia a fim de oferecer aos alunos a oportunidade de participar de oficinas de louças de barro ministradas pelas louceiras durante as aulas de artes, por exemplo. A valorização da cultura local no âmbito escolar teria grande efeito, onde o incentivo atingiria diretamente as presentes gerações para que se apoderassem das técnicas ceramistas de suas mães e avós.

Acredita-se que a perpetuação do ofício das louceiras do Maruanum depende do incentivo do poder público para a organização social das comunidades que formam o Distrito do Maruanum, que apoiadas inclusive pela iniciativa privada poderiam dar um salto para a qualidade de vida com a utilização econômica e sustentável do bem cultural que é o ofício ceramista, aproveitando todas as potencialidades culturais das comunidades de Santa Luzia e Carmo do Maruanum, formadas por pessoas acolhedoras e criativas que precisam de apoio institucional e científico para reconhecerem que a louça do Maruanum é um bem histórico e cultural que pode transformar as suas vidas e torná-las conhecidas por todo o mundo.

\section{Considerações finais}

O advento da Constituição Federal de 1988 ampliou a conceituação de patrimônio cultural brasileiro como bens de natureza material e imaterial e reconheceu o direito ao patrimônio cultural como direito fundamental que indiscutivelmente repercutiu positivamente para que o Estado oferecesse a tutela de tais bens culturais. O Decreto 3.552/2000 que instituiu o Registro de Bens Culturais de Natureza Imaterial foi um destes marcos que reco- 
nheceu saberes, celebrações formas de expressão e lugares como bens que constituem o patrimônio cultural brasileiro.

Amparados pela Constituição Federal de 1988, o Instituto do Patrimônio Histórico e Artístico Nacional (IPHAN) juntamente com demais órgãos estaduais e municipais de Cultura começaram a atuar no mapeamento das referências culturais de cada estado como forma de garantir a preservação e conservação destes bens culturais baseado na legislação especifica para a tutela do patrimônio cultural e nos princípios ambientais. Se o patrimônio cultural é um direito fundamental cabe ao Estado e a sociedade salvaguardarem estes bens por meio do Princípio da Equidade Intergeracional para que as futuras gerações possam ter acesso e fruição aos bens culturais.

Por outro lado, o ofício das louceiras do Maruanum é uma referência cultural tradicional das comunidades que formam o Distrito do Maruanum dentre elas estão Santa Luzia e Carmo do Maruanum, pois está ciência é repassada de mãe para filha, de sogra para nora, de tias para sobrinhas e de primas para primas há bastante tempo, assim criou-se uma identidade cultural, uma memória coletiva, inclusive com elos afetivos de parentesco e herança cultural. Pois, a tradição ceramista envolve questões culturais, tradicionais e religiosas com a crença na Mãe do Barro.

A pesquisa em relação ao ofício das louceiras do Maruanum como patrimônio material e imaterial buscou responder quais os entraves existentes nos órgãos IPHAN (AP) e SECULT (AP) que procrastinam o reconhecimento deste ofício. Os resultados mostraram que praticamente inexistem ações voltadas para tal reconhecimento, o IPHAN (AP) chegou a reconhecer o criar-saber-fazer das louceiras do Maruanum como uma referência cultural inventariada do Estado do Amapá por meio do mapeamento e documentação. Além disso, este órgão federal não possui um quadro técnico que possa atender todas as demandas referentes à gestão do patrimônio cultural do Estado do Amapá, sendo que enfrenta problemas estruturais, financeiros e de pessoal.

Já a SECULT (AP) como órgão estadual não tem um sistema de referências culturais do Estado do Amapá e até o momento não 
executou nenhum projeto de intervenção voltado para o reconhecimento do ofício das louceiras do Maruanum. A importância do registro deste criar-saber-fazer no Livro de Registro de Saberes é uma saída para a perpetuação desse ofício, uma vez registrado, entra o plano de salvaguarda que deve apresentar ações efetivas a fim de preservar e difundir este ofício nas comunidades do Distrito do Maruanum voltados à geração de renda e sustentabilidade ambiental.

Para que aconteça o fortalecimento da Associação das Louceiras do Maruanum, é importante a inserção das louceiras no âmbito escolar, a celebração de parcerias com o poder público e iniciativa privada e principalmente a instituição do turismo comunitário como meio de aferir à comunidade ganho econômico e social. Somente com a intervenção do poder público por meio de investimentos, ações e projetos haverá o reconhecimento dos jovens pela continuidade do ofício ceramista para o fortalecimento da identidade cultural que se encontra desfigurada para a presente geração, portanto é urgente a implantação de políticas públicas culturais nessa região.

\section{Referências}

ALAMI, S.; DESJEUX, D.; GARABUAU-MOUSSAOUI, I. Os métodos qualitativos. Petrópolis, RJ; Vozes, 2010.

COSTA, C. S. da. Patrimônio cultural do Amapá: o caso das louceiras do Maruanum em observância ao Princípio da Equidade Intergeracional.2014. 129f. Mestrado em Direito Ambiental e Políticas Públicas. Universidade Federal do Amapá, Macapá, Amapá.

COSTA, C.S. da; LIMA, W.M.; CUSTÓDIO, E.S. A arte cerâmica do Maruanum: a encantaria como linguagem artística. Revista Identidade, v. 21, n.2, 199-212, jul-dez. 2016.

COIROLO, A. D. Atividades e Tradições dos Grupos Ceramistas do Maruanum (AP). Boletim do Museu Paraense Emílio Goeldi, v. 7, série Antropologia. Belém-PA. 1991. 
Instituto do Patrimônio Artístico Nacional - IPHAN. Dossiê do IPHAN 3: Ofício das Paneleiras de Goiabeiras. Brasília: Distrito Federal, 2006.

Instituto do Patrimônio Artístico Nacional - IPHAN-AP. Referências culturais inventariadas: anexo 01, $\mathrm{n}^{\circ} 20,2009$.

PELEGRINI, S. C. A. e FUNARI, P. P. O que é Patrimônio Cultural Imaterial. São Paulo: Brasiliense, 2008.

PORTA, P. Política de Preservação do Patrimônio Cultural no Brasil: diretrizes, linhas de ação e resultados: 2000/2010. Brasília: IPHAN/Monumenta, 2012.

RICOEUR, P. Teoria da interpretação - o discurso e o excesso de significação. Rio de Janeiro, RJ: Edições 70, 1976.

SANTOS, E. I. dos. Cerâmica de São Gonçalo Beira Rio. Rio de Janeiro, RJ: IPHAN, CNFCP, 2010. 